\title{
Impact of Knowledge Management (KM) on Human Resource Management (HRM) Performance Based on the ACHIEVE Model in Selected Banks of Amman - Jordan
}

\author{
Ghadeer A. Khawaldeh ${ }^{1}$ \\ ${ }^{1}$ Phd Students, The world Islamic Sciences and Education University, Amman, Jordan \\ Correspondence: Ghadeer A. Khawaldeh, Phd Students, The world Islamic Sciences and Education University, \\ Amman, Jordan. E-mail: ghadeerahmad60@yahoo.com
}

Received: December 25, 2019

Accepted: January 21, 2020

Online Published: February 3, 2020

doi:10.5539/ijbm.v15n3p1

URL: https://doi.org/10.5539/ijbm.v15n3p1

\begin{abstract}
The purpose of this study is to explore the influence of knowledge management on human resource management performance based on the ACHIEVE model in selected banks of Amman. The population consisted of 43 employees in 4 Jordanian banks. Data was gathered by a questionnaire according to performance factors of ACHIEVE model. To identify and get rid of irrelevant variables, reliability analysis was conducted. The Kolmogorov-Smirnov normality test was used to examine if variables are normally distributed. As the dependent variable being measured is ordinal, the Friedman test was performed. Furthermore, one-sample t-tests were conducted to investigate the influence of KM on HRM performance. In light of results, KM is significantly impact HRM performance. According to ACHIEVE model, Out of 5 factors, 4 of them were affected by KM with varying degrees. The incentive was the highest factor impact of $\mathrm{KM}$, while an environment is the lowest. The research presents managerial guidance for decision making to develop HRM performance factors, in addition to many theoretical and practical implications. In the end, directions for further research are also included.
\end{abstract}

Keywords: knowledge, knowledge management, human resource management, performance, ACHIEVE model

\section{Introduction}

Prompt changes in technology and global competition required further innovation in organizations. This relies on strengthening employees' capabilities and supplying them with KM support that quickens knowledge processes and improve performance. Since the last century, pioneering companies have started to create a work environment in which they emphasize learning and knowledge management. In knowledge economy, $t$ has been recognized that knowledge is the primary source of wealth creation, as well as managing that knowledge efficiently and effectively is a major success factor for acquisition with a sustainable competitive advantage for firms (Zaim et al., 2018). Ever more, competitive advantage depends on creation, leverage, and a successful application of knowing, particularly knowledge inherent in human origins; effective KM is important element faster and better than competitors (Banerjee, 2013). HRM must be applied to manage human assets by evolving competencies that generate organizational knowledge so as to improve doing and obtain competitive feature (Gope et al., 2018).

(Ananthram et al., 2013), proposed of managing human resources was developed gradually to "the theory of strategically human assets; and KM and strategic agility were the two pillars that this model is constructed on. However, many literature of KM keeps going to focus on technology, like managing information, that in essence, knowledge is considered as an entity that can be captured, manipulated and utilized, this is a risky conception (Gloet, 2006). In general, the major and widely accepted challenge facing executives being in the human art and managing, not in technology (Thite, 2004). So, Gloet, (2006) clarified the importance of improvement of the HRM performance through efficient manage to KM systems within and outside organization, and thus, the conventional concentrate on people managing has been expands to manage firms' capacities, relations, knowledge and learning. Also, Banerjee (2013) Pointed out that human capital should be view beyond a greater extent, as a sustainable and comprehensive viewpoint of individuals, and proposed "the sustainability of human capital" that get about away from a classic view of human capital. 
The accumulated employees' knowledge out of experiences, capabilities, besides the react with environment is critical source to promote and develop performance (Zaim et al., 2018). Knowledge is seen as "a social innovation that results from interaction between individuals and information, especially among communities that work in the fields of communication, the creation of knowledge, sharing of knowledge, and learning" (Gloet, 2006). Thus, the most critical point in HRM is that individuals, their personal relationships, and their knowledge became treated as precious resources (Svetlik \& Stavrou-Costea, 2007). In knowledge economy, the success of human resource management depends on the capacity to exploit the unseen capabilities of individuals in an informal manner, through cooperation, tacit knowledge and learning informally (Thite, 2004).

KM and HRM are two people - based notions concentrate on creating, using and sharing of knowledge (Gope et al., 2018), and both of which cannot be managed in a void (i.e. without individuals) (Svetlik \& Stavrou-Costea, 2007). The fundamentals of HRM strategies for efficient indivuals-focus partnership in knowledge management: trust in the philosophy of human resource, institutionalizing learning, and refine human resource programs in staffing, retention, performance, and managing rewards, and so on (Thite, 2004). Majority of researchers mentioned that knowledge management viewed as a shape of human resource management, particularly, human resource management props employees in knowledge generating and managing through ideas and opinions sharing, and experiences which lead to enhance their performance (Gope et al., 2018). High performance practices and effective management of human resources are integrated processes in the theory of knowledge-based theory for companies seeking excellence, and have a direct relationship with human resource management strategy (Gope et al., 2018). On organizational scale, theory proposes that firms' have to do investments to develop human capital KM so as to improve its performance and employees' performance as well.

Banerjee (2013), Svetlik and Stavrou-Costea (2007), reveals the advantages of utilizing an integrated process among human resource management and knowledge management, where one promote and upholding the other towards improving organizational efficacy as well as performance of employees. (Gope et al., 2018), argue that the practices of human resource management \& KM can develop managerial processes through boosting employees' skills, capabilities; effecting their behaviors and attitudes, increasing incentives, learning capacity, all these practices yields through effective manage of KM systems. Particularly, contribution of KM to HRM is at the top end of value chain as it foremost generate and sustains culture that enhance innovation, creativity and learning, and performance (Thite, 2004). Many studies explored how KM and HRM are strongly connected and influence each other in many fields and provided an empirical support for such a linkage (Akdere, 2009; Arunprasad, 2016; Mir Hamid et al., 2016). Many will be spotlighted in this study; in particular, the effect of knowledge management on human resource management performance. The logic proposition is that KM and HRM must be within each other. Performance defined as "execution, application of any planned or arranged job" (Mir Hamid et al., 2016). Of course, this definition does not include inputs and products only, but also links performance to achievement of a job and its results. Thus, performance viewed as "the method / approach the companies, individuals, and combinations to accomplish the job/tasks.

There is a widespread problem that occurs in the administrative process, that many managers tend to be effective in informing employees of current performance problems, but they are not as much the same in helping them determine the cause of the problem. Namely, many managers are sturdy in identifying a problem or defect, but they are powerless when it comes to analyzing or diagnosing a problem or looking for solutions. This is an important step before the optimization process takes place. For managers to be more effective in assessing performance and solving problems, they need to determine the cause. The ACHIEVE paradigm aims to direct executives specify why problems in performance have been occurred, and thereafter to evolve the strategies for change, as development of an organization that aims to confront and solve these problems.

Utilizing ACHIEVE paradigm enables management to isolate key elements affecting performance. Management experts emphasize that performance is a task of motivation, ability, and conceptualization of roles, company, and environment. In other words, the employee must have a definite degree of willingness to fulfill the task; needful skills, clear understanding, organizational support, and suitable environment. The ACHIEVE paradigm utilizes evaluation and validity (valid and legal personnel practices). The evaluation means that employee needs to know not only what needs to be done, but also the quality of his performance continuously through daily training or official evaluation performance. Validity (credibility of actuality) supplies evidences that all system is exist like analyses of job, staffing, evaluation, coaching, advancement, and discharge.

Also, ACHIEVE is an efficient managing performance frame, and effectively integrates various concepts of management. In addition, through this model, the main procedures demanded becomes easier in the performance planning involving the process of organizational development that can be utilized to foster the performance plans; and develop of the organization and employees. 
To this end, this research examines the interrelation of KM and HRM, and then seeks to investigate the effect of knowledge management on the performance of human resource management on ACHIEVE model in selected Banks of Amman - Jordan. The study is structured as follows, a review of extant literature, conceptual framework and hypotheses development, research method, research findings, and then finally conclusions \& recommendations.

\subsection{Research Problem}

Today's major debate that from its highly skilled human resources and appropriate motivation, business organizations can gain competitive advantage. The relationship between KM and HRM and their impact on performance remains a controversial issue and worthy of study. In Jordan, banking sector plays a vital economic role; accordingly, the efficient HRM performance is very needful. Banks specifically owe their performance improvement as well as employees. To researchers and practitioners, the issue of KM and its impact on performance has long been the focus of their attention. A mostly attractive question for executive managers is how to improve performance in organizations, which requires research into the factors that improve the HRM performance.

However, to the knowledge of the researcher there is a lack of studies that addressed the ACHIEVE model to determine how to improve HRM performance in Jordan context. So this research is an attempt ion to investigate this dialectical relationship. So this research is a preliminary attempt to investigate these dialectical issues. The research problem can be summarized in answering the following question: Based on the ACHIEVE model in selected Banks of Amman - Jordan, what is impact of KM on HRM Performance?

\subsection{Research Significance}

The importance of that study in reflected several focal subjects together whether knowledge management, human resource management and their interrelationship and their unique role in improving the performance of organizations and individuals, that has been in controversy for decades. Another significant feature for this study is the inclusion of the ACHIEVE Model. Also, the results of this study emphasizing that the excellence of organization lies in its capacity to manage knowledge and develop human resources more than physical assets. In addition, the study opened up broad prospects for researchers and scholars for further research, and provides many theoretical and practical implications.

\subsection{Research Questions \& Objectives}

In line with problem statement, the following two questions were formulated:

- Question One: Does KM affect HRM Performance in Jordanian banks?

- Question Two: Does KM influence performance factors of ACHIEVE model in Jordanian banks?

The research objectives were developed as follows based on the above questions:

1. To examine the influence of KM on the performance of HRM in Jordanian a selected banks.

2. To investigate the impact of KM on ACHIEVE model performance factors in selected Jordanian banks.

\section{Extant Literature Review}

\subsection{Knowledge Management and Human Resource Management}

Knowledge as an asset and knowledge management as processes gained significant awareness in both strategic management, and strategic human resource management literature, as a method to enhance performance and obtain competitive business advantage (Ananthram et al., 2013). HRM effectiveness in general relies on KM practices as well as on standards of management's strategic alignment (people, firm, knowledge) and vice versa, KM has to be examined as a factor effecting HRM performance (Figueiredo et al., 2016). From strategic human resource management point of view, the collection of integral human resource activities support organization's strategy leads to sustain a competitive advantage, and human capital which includes skills, knowledge and behaviors, in addition to organizational capital with routine, systems, and tacit knowledge are the highly cited resources in the resource based literature review, which are obtained over time, and make it so difficult to interpret and imitate by competitors (Arunprasad, 2016).

Knowledge management is a "collection of infrastructure, processes, technological, and administrative instruments intended to create, share, implement of information and knowledge within and exterior firms according to (Bounfour, 2003). Also, KM viewed as "a repeated procedures of treating actionable knowledge that outcome through individual, teamwork and organizational learning to enhance the performance (Sunalai, 2015). (Dalkir, 2013), define knowledge management as "implementing a thorough system for promoting the 
development of knowledge in organization ". In this domain, knowledge is composed of individuals' perceptions, expertise, know-how, and values which are justified during societal interactions between participants (Nonaka \& Takeuchi, 2004) to make knowledge having a practical value and embedded in organizational processes as a whole (Davenport \& Prusak, 1998).

Several studies argue that companies have to embrace knowledge managing that facilitates the creation of knowledge and storage (Alavi \& Leidner, 1999) .Knowledge management depends on resource-based views that consider knowledge an invaluable strategic resource, and comprises of information and knowledge which lies at the core of HRM performance development practices. Moreover, KM supports and impacts both models of HRM performance development (learning and performance) (Akdere, 2009). Thus, Knowledge management practices so firms can harness their actionable knowledge efficiently to develop their performance (Sunalai, 2015). In general, HR can participate to innovations by promoting organizational activities that better manage the flow of knowledge (i.e., acquire, generate, storage, share, utilize, and evaluate) throughout the firm (Sunalai \& Beyerlein, 2015).

Alavi and Leidner (1999) specified three primary components of knowledge management, (i.e. information, technology, and culture). In the first component, managers view not only knowledge management as a system for storing and retrieving knowledge, but also a way to track who maintains and transfer knowledge. In technological side, managers link KM with available technology (Mir Hamid et al., 2016). This technology forms the basis for the works of organization, including the Internet and the intranet, data, and tools available, like decision-making tools, search engines and multimedia materials (Alavi \& Leidner, 1999). The technology capacities involves: the infrastructure of information technology, integrated databases, the ability to self-operate existing systems, expert systems, and a joint collection of web and e-mail products (Banerjee, 2013). In culture side, organizational learning, communication, and nurturing intellectual property are the components of knowledge management (Alavi \& Leidner, 1999). A cultural ability includes teamwork as well as sharing of knowledge (Wild \& Kenneth, 2008). Knowledge management strategies cannot be successfully implemented without a proper cooperative culture based on trust, if the culture of the organization does not facilitate and encourage the sharing and distribution of knowledge, then knowledge management will encounter many challenges (Tiwari and Saxena, 2012).

For attaining competitive advantage, HRM is a significant matter as it is a heart source to gain a competitive advantage (Tiwari \& Saxena, 2012), define human resource management as "a process to expand experience for boosting performance and its areas that contain firms, teamwork, individuals and communities of practice. Human resource management can transform another resources into output (product and service) (Yeganeh \& Su, 2008). Some researchers have indicated that people management is harder than technology management (Akdere, 2009). Moreover, competitors can imitate other resources as technology but HR is not imitated. Companies that are effectively managed and control the expertise and knowledge embedded in the minds of employees will be able to create greater value to achieve competitive advantage and improve performance (Zakaria \& Hashim, 2015).

Based on the above discussion, human resource management is comprehend as "a group of activities and regulations that impact attitudes, policies, staff performance aiming to leverage competitiveness, learning ability, and improve performance " (Zakaria \& Hashim, 2015; Zaim et al., 2018). Gope et al. (2018) pointed out that the practices of human resource management that boost individual's learning, motivate and retain employees in order to enhance knowledge acquisition and sharing, all of which will improve organizational performance. Moreover, their findings revealed that classic roles of human resource management practices are improved to support the achievement of business goals, supporting employees, and develop the performance. As proposed by (Bontis \& Serenko, 2007), employees' capabilities and performance relies on organizational support (help), coaching, loyalty, experiences, skills and incentive systems.

Arunprasad (2016) indicated that strategic human resource management practices are significantly and positively related to knowledge management and learning outcomes. For example, ability and evaluation are the factors that significantly contributed to enhance performance. Therefore, according to (Theriou \& Chatzoglou, 2014), organizations that follow better human resource management practices fulfill high performance through creating human resource practices supported by knowledge management and organizational learning capacity, and in return, building of organizational capabilities. It is proposed that better human resource management practices are not only related directly to organizational capability, but also indirectly related to the processes of organizational learning capability and knowledge management. Indeed, human resource management acquires a primary role in potentiating and facilitating knowledge management and learning processes (Figueiredo et al., 2016). Thus, if human resource management is on managing individuals efficiently, and if people's most 
valuable resource is knowledge, then KM and HRM are closely interconnected (Svetlik \& Stavrou-Costea, 2007).

Studies of an alternate point of views have examined the type and quality of KM and HRM relationships, it is vastly agreeable that human resource management is not knowledge management (Pillania, 2009). (Svetlik \& Stavrou-Costea, 2007), argues that knowledge management is more multifaceted than human resource management as it includes managing intellectual property rights in addition to transfer of individual and organizational know-how. However, (Svetlik \& Stavrou-Costea, 2007) stated that KM and HRM share common practices, aims, and strategies when creating business units, groups, cross-functional collaboration, communication flow, and networks inside organization and across its borders. Further, they proposed an integrative approach among knowledge management and human resource management, so that when compare knowledge management cycle with human resource management processes, we will find that different activities are common between both. For a long time, literature has supported the claim that employees are the most significant organizational asset, particularly when it comes to achieve an effective knowledge management processes (Nilsson \& Ellström, 2012; Edvardsson, 2008; Pillania, 2009; Santoro \& Usai, 2018).

Employees are the vehicles for knowledge creation, sharing and implementation. (Nilsson \& Ellström, 2012), emphasized that the general organizational success is increasingly associated with identifying, recruiting, managing, and retaining high performers or talented individuals to meet the present and future demands of an organization. Therefore, the core purpose of the HR function is to develop, select and hire people, train and develop the staff, evaluate their performance, reward them and create a culture of learning to support and achieve the business strategy (Edvardsson, 2008). In fact, human capital advantage stems from having more capable people than the competition (Medina \& Medina, 2015). Shaw et al. (2013) argue that human capital can meet the criteria of sustained advantage, when HRM investments are aimed at increasing the knowledge and skills of the workforce and also to tightly integrate the human capital.

Therefore, HRM activities, such as recruitment and selection, education and training, performance management and reward systems, are essential for managing knowledge properly (Santoro \& Usai, 2018) and contribute instrumentally to improving the knowledge flow, i.e., acquisition, transfer and its integration in the organization (Figueiredo et al., 2016). Zhou et al. (2018) found that several HRM practices (namely, internal communication, training and performance appraisals) play an important role in helping firms to build absorptive capacity and to enhance knowledge transfer during mergers and acquisitions. Knowledge sharing practices must be integrated into strategic business objectives, human resources practices, and the organization's culture so as to encourage and support on-going collaborative behavior (O'Neill \& Adya, 2007).

Some scholars have highlighted recently "Knowledge-based HRM" including those HRM practices purposefully designed to enhance knowledge processes within an organization (Kianto et al., 2017) with the need to reposition its functions, orienting them towards strategic capacities of knowledge. That is to manage knowledge workers, to construct a value from knowledge and to assess the risk of knowledge loss (Figueiredo et al., 2016). For instance, (Hussinki et al, 2017) divided HRM practices into several categories such as heterogeneous workgroups and brainstorming commitment-based HR practices (e.g., employee empowerment and career development) and knowledge-based (e.g., recruiting, professional development, and employee retention).

\subsection{The Achieve Model}

The ACHIEVE paradigm comprises seven elements regarding to efficiently performance management: Ability (knowing and skillfulness), Clarity (grasp/role perception), Help (organizational backing), Incentive (motive /readiness), Evaluation (feedback), Validity (correct and legal personnel practices), and Environment (environmental proper) (Hersey \& Goldsmith, 1980). These factors will be briefly discussed within this section. This model is designed to assist and guidance managers in identifying the causes of performance problems, and providing an effective strategies for better change and finding solutions. This model also takes into account the analysis of human performance, taking into account the identification of the primary elements that impact employee's performance, and then presents them to management to take them into consideration and use for many purposes, such as evaluation and feedback (Hersey \& Goldsmith , 1980). Exclusion of factors that influence the performance management is the first step in evolving this model. Performance is influenced by incentive and ability according to (Atikson \& Reitman, 1995) confirmation. In other words, employees must have sufficient skills, experience, knowledge and readiness to complete their tasks. These ideas were evolved by including knowledge / knowledge management to understand of work because of their great impact on performance. However, even if the employee has the skill and the complete readiness to do a job, it will be benefic when 
employee also has an evident perception of what he will make, how will do, and hence the clarity of roles is important issue (Lawrence \& Lorsch, 1997).

Lawrence and Lorsch (1997) addressed this from another corner, and concluded that performance is not only related to individual's behaviour, but also to organizational support and environment fit. The skills, abilities and incentives, is not enough for employee to be an effective, besides, he should receive an organizational support, help, evaluation, and guidance required, and adapt his job to the organization's needs and environment fit (Nasim Yousef et al., 2015). This model uses other factor of performance management, namely evaluation that employee should be understanding not only of what he should do, but also of how to behave based on prevalent problems in the work (Hersey \& Goldsmith, 1980).

A - Ability (knowledge and skills) refers to" employee's knowing, expertise and high skills to accomplish successfully a certain job (Robbins, 2009). The ability represents an individual's knowledge and skills that make doing the task in an optimal method possible matter. Organization's knowledge management and well-qualified employee, of course will influence performance (Yaghubi et al., 2011). The ability involves knowledge and skills that are related to the work (Hersey et al., 1996), in addition to knowledge the work formally or informally and the capability to achieve a required job(s).

It is worth mentioning to remember that individuals are not often competent. An ability fundamental component contains related to the learning formally and informally, previous expertise and job related competences (prospects/ features which support fulfillment the job successfully). When analyzing performance of employees, managers have to ask the following question: "Does employee have the necessary skills and knowledge to successfully accomplish the job?" If individual has a problem in capacity, solutions may consist of a particular training, formal educational courses, or reassignment of particular tasks or liabilities. These alternatives should be taken into account from the point of view of relevance and effectiveness.

C - Clarity (understanding the role). Clarity refers "to what extent does employee realizes the job, and willingness to accept of when, what, and how to do the job. It represents the understanding and acceptance the roles to undertaking the task in the appropriate place and time. Employee cannot fully understand the problem unless the goals, priorities, solutions, and roles are sufficiently clear. Clarity or (role understanding) includes understanding and acceptance of job procedures (the sense of where and how this is achieved). Managers should inform employees of the organization's clear goals (vision and mission), problems facing the work, and priorities, how goals achieved, and problem solving (Rezaeeian, 1993).

Employees need clarity in goals, objectives, and roles in order to have a deep understanding of what they will do. If the employee has a problem with clarity, lack of understanding, and in other work issues, thus the problem is in planning. In many situations, verbal convention on objectives achievement is not enough. Manager should affirm that all business aims are formally documented and attainable for review, and employee should be prompted to ask questions for further clarification.

H - Help (organizational support). This factor refers to" organizational help or support that employee needs to effectively completion the job". This support involves a sufficient budget, equipment, facilities, needful support from other business divisions, product availability, quality, adequate support from human resources management, and any other things required for completion the task. Organizational support also includes material and moral support. If there is a lack of support (help), managers should clearly identify where the problem exists. If the problem is lack of money, human resources, equipment, or facilities, manager should see whether the necessary resources could be acquired in a cost-effective manner. If the resources cannot be acquired, the manager may have to revise objectives to avoid holding employees responsible for circumstances beyond their control.

I - Incentive (motivation). Incentive refers to "the rewards (tangible or intangible) that will fulfill individual's needs". It is the willingness of individuals to a successfully conduct a specific task (Yaghubi et al., 2011). Motivating employee means encouraging him to do a specific task and complete it successfully (Hersey et al., 1996). Employees can be motivated to be successful completion of the tasks to get physical and moral rewards. If an organization has many incentives, in return employees should be informed of the existence of punishments as well. Humans have different kinds of needs; some are economic, while others are social. As well, employees needs include a sensible salary, the security, group belonging, appreciation, growth and efflorescence, satisfaction, and identity sense. Achieving balance and fairness in these needs helps boost incentives, achieve organizational goals, implement relevant plans, and improve performance (Abol-alaei, 2010).

It is important to recall that majority of employees are not equally motivated to accomplish the same tasks in evaluating incentive. Many tend to be very motivated toward completion of tasks successfully that will bring them rewards. If employee has a problem in incentive, the first step is to check the justice utilizing of rewards 
and punishments. Employee must obviously understand that perform this task is related to pay, promotion, acknowledgement, and job security. However, managers from time to time hope that employees will engage in particular behaviors without rewarding, but employees have a tendency in natural to follow tasks that are rewarded and to avoid the tasks that are not rewarded.

E - Evaluation (coaching and performance feedback). Evaluation refers to informal daily performance feedback in addition to formal periodical checks. It applies to day - day performance appraisal and to the occasional review. An appropriate and ongoing evaluation allows employee to be informed to the progress and work quality (Haghighi, 2001). The aim of this kind of evaluation is a daily informal offer on performance to the employer and formal periodic checkup (Rezaeeian, 1993). The evaluation aims to ensure that employee's behavior and performance are consistent with organizational standards, objectives, and expectations. In addition, it assists diagnose employee's strengths and weaknesses, supplies employees with their behavior record and performance. To evaluate employee's behavior and performance, firms only have to depend on accurate information (Abol-alaei, 2010).

An efficient feedback processes permits employees realize how well they are doing the job on a regular basis. It is illogical to expect employees to improve their performance without realizing that there are problems with it. Individuals ought to know how they are being appraisable on a regular basis before their formal periodic evaluation occurs. Many performance problems can be caused by a lack of necessary training, and performance feedback. If there is an evaluation problem, it may be caused by the lack of daily feedback on both efficient and inefficient performance. Many managers tend to concentrate on the bad news and forget to recognize when things are going very well. Recognition for a job well done can be a pivotal part of the continuing evaluation increase motivation and cost the organization very little. One method that helps to spotlight extremes in performance is the "significant incident" process, which includes formally documenting highly positive or negative performance (Abol-alaei, 2010). This ensures that the employee receives feedback that is part of the formal record (Yaghubi et al., 2011).

$\mathrm{V}$-Validity (valid and legal personnel practices). The term validity refers to the actuality, suitability, and validity of human resources decisions made by manager. Managers need to make assured that decisions about employees are proper in light of laws, social practices, and company policies. Managers' decision should be accompanied by evidence and be founded on the performance-oriented policy. Managers' should make assured that personnel practices do not distinguish against any particular group or individual, and should be aware that organizations need valid and legal performance evaluations, training and promotion criteria selection techniques, and so on. If there is a validity problem, managers should check the credibility of their assumptions. Experiences should be documented and justified on the basis of performance-oriented criteria. If managers are unsure of validity issues, they should discuss it with the personnel department or with the organization's leaders.

E - Environment (environmental fit). The term environment refers to the external factors that can impact performance even if the employee has the ability, clarity, help, and incentive required to perform the job .It includes competition, changes in market conditions, government regulations, facilities, supplies, and so on. Fitness of environmental factors refers to the external factors accompanied with ability, clarity, and support (Haghighi, 2001). Employees should not be rewarded or reprimanded for their performance if there is an environmental problem outside their control. In general, employees should be expected to perform at a level consistent with the restrictions imposed on their work environment.

\section{Conceptual Framework \&Hypotheses Development}

To achieve the research objectives, for independent variable, the researcher adopt KM (Alavi \& Leidner, 1999) model which consist of culture, information, and technology to measure how these KM components will impact HRM performance, and for dependent variable HRM performance, the ACHIEVE model of (Hersey \& Goldsmith, 1980). Out of seven performance factors of ACHIEVE model, only five were selected as the base model in this study, namely incentive, environment, ability, evaluation, and clarity. The following diagram (Figure 1) demonstrates the conceptual framework of the research: 


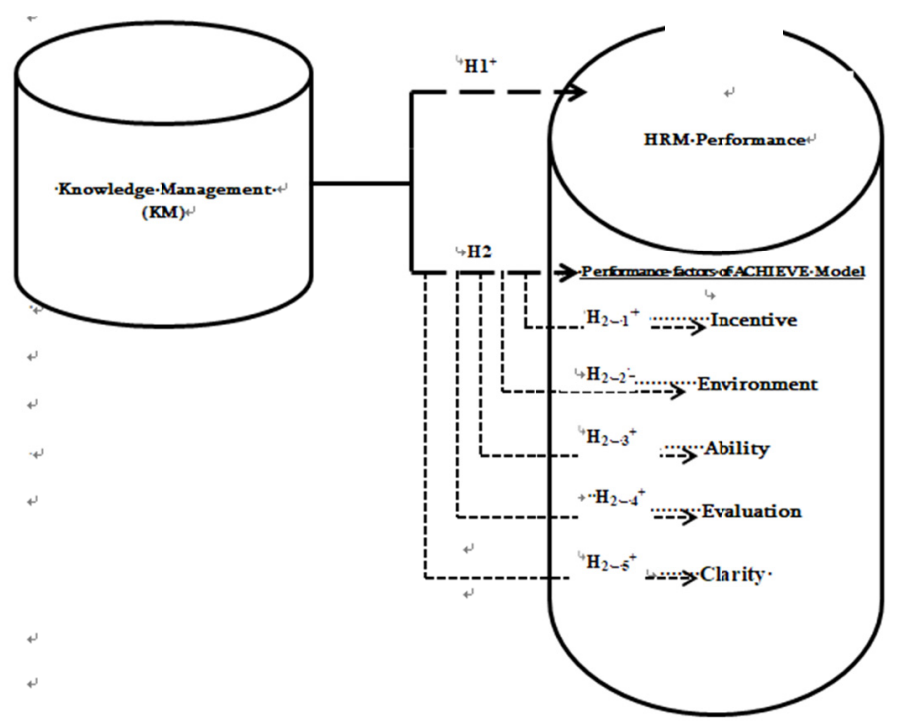

Figure 1. Conceptual model

Based on the above conceptual framework, the following two hypotheses were developed:

Hypothesis One (H1): KM significantly impact HRM performance.

Hypothesis Two (H2): KM significantly influences HRM performance. Therefore, H2 be composed of 5 sub-hypotheses depicted below:

Hypothesis One (H1): KM significantly impact HRM performance.

Hypothesis Two (H2): KM significantly influences HRM performance. Therefore, $\mathbb{H} 2$ be composed of 5 sub-hypotheses depicted below:

Hypothesis 2-1: $\mathbf{H}_{(21)}$ : Incentive is greatly affected by KM.

Hypothesis 2-2: $\mathbf{H}_{(22)}: \mathrm{KM}$ has a significance effect on environment.

Hypothesis 2-3: $\mathbf{H}_{(23)}$ : Ability is significantly influenced by KM.

Hypothesis 2-4: $\mathbf{H}_{(24)}$ : Evaluation is significantly influenced by KM.

Hypothesis 2-5: $\mathbf{H}_{(25)}$ : Clarity is significantly affected by KM.

\section{Method}

The banks under research were Arab Bank, Iskan Bank, and Islamic Bank, Cairo Amman Bank in Amman city working in Amman city where about 52 employees had. The population comprises of 43 employees, 28 male $(65.1 \%)$ and 15 female $(34.9 \%)$ in three age groups, $(20.3 \%)$ aged $20-30,(38.6 \%)$ aged $31-40,(41.1 \%)$ aged more than 40 years old. Among these, 30 people $(71.4 \%)$ had bachelor's degree, and $13(28.6 \%)$ possessed graduate degree. $9(20.9 \%)$ had work experience less than 5 years, $15(34.9 \%)$ with the experience of 5 to less than 10 years, and 19(44.2\%) were employed in those banks.

The research was an applied study, and performed by utilizing a survey method. To answer research questions, data was gathered out of ACHIEVE questionnaire relating to performance components of this model. The questionnaire be composed of 21 questions categorized into 5 variables namely: incentive, environmental factors, ability, evaluation and clarity arranged based on 5 - Likert scale. In this scale, the score 1, 2, 3, 4, and 5 were referred to: strongly agree, agree, neutral, disagree strongly, and disagree respectively. To assure validity, feedback was requested from several university professors in HRM and managers in targeting banks . Reliability analysis was performed to identify and dispose of variables unrelated to the research, and yielded a Cronbach's alpha value as shown in Table 1. The questionnaires were distributed among 51 employees. A total of 47 returns were returned. Of those returns, 43 were usable for further analysis. Four questionnaires had to be neglected due to incompleteness. Cronbach's alpha was used to determine the reliability of measuring instrument. 
Table 1. Cronbach's alpha values

\begin{tabular}{lll}
\hline Factor & No.of items & Cronbach's alpha \\
\hline Incentive & 5 & 0.75 \\
Environmental Factors & 4 & 0.71 \\
Ability & 3 & 0.83 \\
Evaluation & 4 & 0.73 \\
Clarity & 5 & 0.86 \\
\hline
\end{tabular}

Table 1 show that calculated Cronbach's alpha for all variables was greater than 0.70 which was indicative of the acceptable reliability for gathered data. To analyze the impact of KM on HRM performance, and performance factors of ACHIEVE model, one-sample t-tests were conducted. Further, Kolmogroph - Esmirnov test was employed to consider the normality of variables' distribution. The test evidenced the variables homogeneity with normal distributions as demonstrated in Table 2. To rank the impact of KM on the ACHIEVE model, Friedman ranking test was performed. The results are demonstrated in Table 3 and Table 4. One sample t-tests with a cut-off score of three were conducted to test the hypotheses. Analysis results appear in Table 5.

\section{Research Findings}

Table 2. Results of normality test

\begin{tabular}{lcllll}
\hline & incentive & environment & ability & evaluation & clarity \\
\hline Respondents No. & 43 & 43 & 43 & 43 & 43 \\
Mean & 4.20 & 3.04 & 4.11 & 3.80 & 3.61 \\
SD & 0.44 & 0.67 & 0.43 & 0.56 & 0.81 \\
Z & 1.48 & 1.63 & 1.64 & 1.29 & 1.34 \\
2 - tailed Sig. & 0.06 & 0.05 & 0.05 & 0.06 & 0.05 \\
\hline
\end{tabular}

The test revealed homogeneity of variables with a normal distribution. As table 2 shows, for all variables significance is equal to or bigger than 0.05 , this indicates that variables had a normal distribution. This permitted conducting parametric tests.

Table 3. Results of Friedman test

$\mathrm{N}=43$ Chi-square $=129.82 \mathrm{DF}=7$ Sig.level 0.00

Table 3 demonstrates, statistically significant differences emerged in the impact of the independent variable(KM) on dependent variables- HRM performance and (ACHIEVE variables). This indicates that the estimated significance of the 5 variables is less than 0.05 .

Table 4. Results of Friedman test for ranking of the ACHIEVE factors

\begin{tabular}{lll}
\hline variables & Ranking mean & Rank \\
\hline Clarity & 3.87 & 4 \\
Ability & 5.31 & 2 \\
Incentive & 5.54 & 1 \\
Evaluation & 4.19 & 3 \\
Environmental factors & 2.17 & 5 \\
\hline
\end{tabular}

Table 4 shows, from among 5 performance factors of ACHIEVE model, the broadest impact has been upon four of them namely (clarity, ability, incentive, and evaluation). The biggest effect of KM has been upon incentive with mean $(\mathrm{M}=5.54)$. While, comparison with other variables, the mean of environment is more dispersed and is the lowest $(\mathrm{M}=2.17)$. 
Table 5. T-test results

\begin{tabular}{lccccccl}
\hline & N Mean & t DF & & \multicolumn{2}{l}{ Sig.level Mean difference } & $\begin{array}{l}\text { CI } \\
0.95\end{array}$ \\
& & & & & & & LL UL \\
\hline$H 1$ & 43 & 3.71 & 15.54 & 42 & 0.00 & 0.71 & 0.620 .80 \\
$\left.H_{(2} 1\right)$ & 43 & 4.20 & 22.13 & 42 & 0.00 & 0.20 & 1.091 .33 \\
$H_{(22)}$ & 43 & 3.04 & 0.72 & 42 & 0.47 & 0,04 & -0.090 .23 \\
$H_{(23)}$ & 43 & 4.11 & 2081 & 42 & 0.00 & 1.11 & 1.001 .22 \\
$H_{(24)}$ & 43 & 3.80 & 11.49 & 42 & 0.00 & 0.80 & 0.660 .94 \\
$H_{(25)}$ & 43 & 3.61 & 7.65 & 42 & 0.00 & 0.61 & $0 . .450 .80$ \\
\hline
\end{tabular}

According to Table 5, the hypotheses were examined, and the results were depicted below:

Hypothesis One (H1). KM significantly impacts HRM performance. Significance of this variable was lower than probability error(0.05); the lower and upper limits (LL \& UL) of confidence interval (CI) $(0.62-0.80)$ positive; the mean was bigger than 3. Thus, hypothesis one was supported.

Hypothesis 2-1:H $\mathrm{H}_{(2)}$ : incentive is greatly affected by $\mathrm{KM}$. This hypothesis was confirmed, because this factor's significance level was lower than error probability, i.e. 0.05, in addition, since the LL and UL (1.091.33) positive, and mean of this factor was bigger than 3 .

Hypothesis 2-2: $\boldsymbol{H}_{(22)}-\mathrm{KM}$ has a significance effect on environment. Significance level of this factor was higher than error probability(0.47). Moreover, since the LL was negative(-0.09), UL was positive( 0.23$)$, and the mean of this factor was less than 3, the hypothesis was rejected.

Hypothesis 2-3: $\boldsymbol{H}_{(23)}$ - Ability is significantly influenced by KM . Significance level of this factor was less than error probability error; LL and UL were positive $(1.00-1.22)$; and the mean of this factor was bigger than 3. Thus, the hypothesis was confirmed.

Hypothesis 2-4: $\boldsymbol{H}_{(24)}$ - Evaluation is significantly influenced by KM. This hypothesis was supported because the significance level of this factor was lower than 0.05 , i.e. error probability. Furthermore, since LL and UL were positive $(0.66-0.94)$, and the mean of this factor was bigger than 3 .

Hypothesis 2-5: $\boldsymbol{H}_{(25)}$ - Clarity is strongly affected by KM. This factor's significance level was less than error probability error. Besides, the LL and UL were positive $(0.45-0.80)$, and the mean was greater than 3 . So, the hypothesis was supported. Overall, from among $5 \mathrm{sub}$ - hypotheses 4 were supported. Therefore, it is concluded that KM significantly affect HRM performance in the targeted Jordanian banks.

\section{Conclusions \& Recommendations}

The purpose of this study was to investigate the impact of KM on HRM performance. The overall conclusion of this investigation is that KM significantly impacts HRM performance. This confirms that companies that create and share intellectual capital and invest largely in KM systems can have a dominant position in local and global markets, and obtaining a sustainable competitive advantage. Also, this result calls attention to the need to focus effort on converting organizations to learning organizations and to enhance learning culture. The individual's features of human resource managers and organizational culture play a crucial role in determining data collection, sharing of information, and processes of knowledge creation (Bock \& Kim, 2002). This impact the organization's capacities being to be a learning organization, where information is utilized in making sense, knowledge construction, and decision - making processes (Ravishankar\& Pan, 2008), and promote performance (Choi \& Davis, 2008).

KM significantly influences HRM performance factors of ACHIEVE model. Based on the ACHIEVE model, incentive, ability, clarity, evaluation with varying degrees except environment affect employee performance. The findings are consistent with (Mir Hamid et al, 2016; Nasim Yousef et al., 2015), studies. With regard to incentive, it is recommended that firms should provide the actual support, encouragement, rewards, bonus, and so on for creative employees and those who all the time look for knowledge and authorizes them take part in organizational decision- making. Regarding ability, it is recommended that firms force stress towards succession culture, and empowering employees via training, holding seminars and conferences, taking employee to business-oriented entertainment, guiding, understanding role playing, group working, and other managerial styles (Noh et al., 2014).

The findings indicated also that clarity is influenced by KM. Therefore, it is recommended that organization 
make employees familiar with their rights, duties, cross expectations, goals, organizational plans, and performance evaluation standards. Other result was that KM significantly impact on evaluation, it seems to logic to suggest that firms place big confirmation on employees' learning, rather than on their committed errors, also on attainment of further knowledge, experience, and information from the side of managers which leads to push employee performance. Finally, the study indicated that KM does not significantly impact environment. So, established an environment where information are shared and used easily between employees may support boost employees' knowledge and improved their performance.

As any other research, there are some limitations. First, data were obtained through quantitatively approach (namely using questionnaire). Future research should qualitatively examine the effect of these factors on performance. Second, this study addressed the issue in one city exclusively which may not be representative of other parts of the country or in other contexts, so we may not be able to generalize the results. Comparison of various cities or contexts may change the results. However, future studies could address this issue in other contexts, particularly in Jordan. Third, the sample size used is relatively small, so future studies should use larger sample, and findings need to be interpreted accurately regarding the generalizability. However, this study is a promising outset to further research, the researcher also suggests the inclusion other performance factors of the ACHIEVE model such as organizational support, help and validity.

\section{References}

Abol-alaei, B. (2010). Performance management, managers evaluate and improve employee performance (1st ed.). Tehran: Industrial Management Institute Press.

Akdere, M. (2009). The role of knowledge management in quality management practices: Achieving performance excellence in organizations. Advances in Developing Human Resources, 11(3), 349-361. https://doi.org/10.1177/1523422309338575

Alavi, M., \& Leidner, D. E. (1999). Knowledge management systems:Emerging views and practices from the field. Paper presented at the International Conference on System Sciences. Hawaii.

Ananthram, S., Nankervis, A., \& Chan, C. (2019). Strategic human asset management: Evidence from North America. Personnel Review, 42(3), 281-299. https://doi.org/10.1108/00483481311320417

Arunprasad, P. (2016). Guiding metaphors for knowledge-intensive firms: Strategic HRM practices and knowledge strategies. International Journal of Organizational Analysis, 24(4), 743-772. https://doi.org/10.1108/IJOA-07-2015-0887

Atikson, J. W., \& Reitman, W. R. (1995). Performance as a function of motive strength and expectancy of soal-attainment. Journal of Abnormal \& Social Psychology, 53, 361-366. https://doi.org/10.1037/h0043477

Banerjee, P. M. (2013). Sustainable human capital: Product innovation and employee partnerships in technology firms. Cross Cultural Management. An International Journal, 20(2), 216-234. https://doi.org/10.1108/13527601311313481

Bock, G. W., \& Kim, Y. G. (2002). Breaking the myths of rewards: An exploratory study of attitudes about knowledge sharing. Information Resources Management Journal, 15(2), 14-21. https://doi.org/10.4018/irmj.2002040102

Bontis N, Serenko A.(2007). The moderating role of human capital management practices on employee capabilities. Journal of Knowledge Management, 11(3), 31-51. https://doi.org/10.1108/13673270710752090

Bounfour, A. (2003).The management of intangibles, the organization's most valuable assets. London: Roudlege.

Choi, B., Poon, S. K., \& Davis, J. G. (2008). Effects of knowledge management strategy on organizational performance: A complementary theory-based approach. The International Journal of Management Science, 36(1), 234-251. https://doi.org/10.1016/j.omega.2006.06.007

Dalkir, K. (2013). Knowledge management in theory and practice. Routledge.

Davenport \& Prusak. (1998). Working Knowledge: How Organizations Manage What They Know. Boston: Harvard Business School Press. https://doi.org/10.4324/9780080547367

Edvardsson, I. R. (2008). HRM and knowledge management. Employee Relations, 30(5), 553-561. https://doi.org/10.1108/01425450810888303 
Figueiredo, E., Pais, L., Monteiro, S., \& Mónico, L. (2018). Human resource management impact on knowledge management: Evidence from the Portuguese banking sector. Journal of Service Theory and Practice, 26(4), 497-528. https://doi.org/10.1108/JSTP-12-2014-0269

Gloet, M. (2006). Knowledge management and the links to HRM: Developing leadership and management capabilities to support sustainability. Management Research News, 29(7), 402-413. https://doi.org/10.1108/01409170610690862

Haghighi, M. A. (2001). Organizational behavioral management. Tehran: Termeh.

Hersey, P., \& Blanchard, K. H., \& Johnson, D. E. (1996). Management of organizational behavior: Utilizing human resource. Upper Saddle River, NJ: Prentice Hall.

Hersey, P., \& Goldsmith, M. (1980). A situational approach to performance planning. Training \& Development Journal, 34(11), 38-44.

Hussinki, H., Kianto, A., Vanhala, M., \& Ritala, P. (2017). Assessing the universality of knowledge management practices. Journal of Knowledge Management, 21(6), 1596-1621. https://doi.org/10.1108/JKM-09-2016-0394

Kianto A, Sáenz J, Aramburu N.(2017). Knowledge-based human resource management practices, intellectual capital and innovation. Journal of Business Research, 81, 11-20. https://doi.org/10.1016/j.jbusres.2017.07.018

Lawrence, P., \& Lorsch, J. (1997). Differentiation and integration in complex organizations. Administrative Science Quarterly, 12(1), 1-30. https://doi.org/10.2307/2391211

Medina, R., \& Medina, A. (2015). The competence loop: Competence management in knowledge-intensive, project-intensive organizations. International Journal of Managing Projects in Business, 8(2), 279-299. https://doi.org/10.1108/IJMPB-09-2014-0061

Mir, H. R., Torabia, A. K., \& Hussein, F. (2016). An Investigation of the Impact of Knowledge Management on Human Resource Performance in Management of Keshavarzi Bank Branches in Tehran. $3^{\text {rd }}$. International Conference on New Challenges in Management and Business: Organization and Leadership, 2 May 2016, Dubai, UAE. Procedia - Social and Behavioral Sciences, 230, 471-481. https://doi.org/10.1016/j.sbspro.2016.09.059

Nasim, Y. S., Seyyed, M. T., \& Abbas, A. (2015). The interaction of the performance factors in ACHIEVE model: A study in Iran. International Journal of Organizational Leadership, (4), 170-180. https://doi.org/10.33844/ijol.2015.60205

Nilsson, S., \& Ellström, P. E. (2012). Employability and talent management: Challenges for HRD practices. European Journal of Training and Developmen, 36(1), 26-45. https://doi.org/10.1108/03090591211192610

Noh, M., Kim, H., \& Jang, H. (2014). Learning performance and business performance of knowledge management organizations: The moderating effect of technology capability. Information Development, 30(5), 1-18.

Nonaka \& Takeuchi. (2004). Knowledge creation and dialectics. In Takeuchi H, Nonaka I. (Editors), Hitotsubashi on Knowledge Management (pp. 1-28). Singapore: John Wiley \& Sons (Asia).

O'Neill, B. S., \& Adya, M. (2007). Knowledge sharing and the psychological contract: Managing knowledge workers across different stages of employment. Journal of Managerial Psychology, 22(4), 411-436. https://doi.org/10.1108/02683940710745969

Pillania, R. K. (2009). Demystifying knowledge management. Business Strategy Series, 10(2), 96-99. https://doi.org/10.1108/17515630910942223

Ravishankar, M. N., \& Pan, S. L. (2008). The influence of organizational identification on organizational knowledge management (KM). The International Journal of Management Science, 36(1), 221-234. https://doi.org/10.1016/j.omega.2006.06.006

Rezaeeian, A. (1993). Organizational behavioral management: Concepts, skills, and exercise. Tehran: Tehran University Press.

Robbins, S. P. (2009). Organizational behavior. San Diego: San Diego State University. 
Santoro, G., \& Usai, A. (2013). Knowledge exploration and ICT knowledge exploitation through human resource management: A study of Italian firms. Management Research Review, 41(6), 701-715. https://doi.org/10.1108/MRR-07-2017-0215

Shaw, J. P., Park, T., \& Kim, E. (2013). A resource-based perspective on human capital losses, HRM investments, and organizational performance. Strategic Management Journal, 34, 572-589. https://doi.org/10.1002/smj.2025

Sunalai, S. (2015). Knowledge Management Systems in Higher Education Institutions in Thailand: A Holistic Model of Enablers, Processes, and Outcomes [dissertation]. Texas A\&M University.

Sunalai, S., \& Beyerlein, M. (2015). Exploring knowledge management in higher education institutions: Processes, influences, and outcomes. Academy of Educational Leadership Journal,19, 289-308. Retrieved from http://search.proquest.com/docview/1768629497?accountid=44522

Svetlik, I., \& Stavrou-Costea, E. (2007). Connecting human resources management and knowledge management. International Journal of Manpower, 28(3/4), 197-206. https://doi.org/10.1108/01437720710755209

Theriou, N. G., \& Chatzoglou, P. (2014). The impact of best HRM practices on performance-identifying enabling factors. Employee Relations, 36(5), 535-561. https://doi.org/10.1108/ER-02-2013-0025

Thite M.(2004).Strategic positioning of HRM in knowledge-based organizations. The Learning Organization, 11(1), 28-44. https://doi.org/10.1108/09696470410515715

Tiwari, P., \& Saxena, K. (2012). Human resource management practices: A comprehensive review. Pakistan Business Review, 9(2), 669-705.

Wild, R., \& Kenneth, G. (2008). A model of information technology opportunities for facilitating the practice of knowledge management. The Journal of Information Knowledge Management Systems, 38(4), 490-506. https://doi.org/10.1108/03055720810917732

Yaghubi, M., Karimi, S., Javadi, M., \& Nikbakht, A. (2011). Relationship between components of organizational learning and knowledge management in employees of the selected hospitals in Isfahan province. Journal of Health Management, 13(42), 65-75.

Yeganeh, H., \& Su, Z. (2008). An examination of human resource management practices in Iranian public sector. Personnel Review, 37(2), 203-221. https://doi.org/10.1108/00483480810850542

Zaim, H., Keceli, Y., Jaradat, A., \& Kastrati, S. (2018).The effects of knowledge management processes on human resource management: Mediating role of knowledge utilization. Journal of Science and Technology Policy Management, 9(3), 310-328. https://doi.org/10.1108/JSTPM-02-2018-0011

Zakaria, N. S., \& Hashim, M. K. (2015). The impact of employment relations practices on performance of Malaysian SMEs: The conceptual framework.

Zhou, A. J., Fey, C., \& Yildiz, H. E. (2018). Fostering integration through HRM practices: An empirical examination of absorptive capacity and knowledge transfer in cross-border M\&As. Journal of World Business, 7. https://doi.org/10.1016/j.jwb.2018.05.005

\section{Copyrights}

Copyright for this article is retained by the author(s), with first publication rights granted to the journal.

This is an open-access article distributed under the terms and conditions of the Creative Commons Attribution license (http://creativecommons.org/licenses/by/4.0/). 